\title{
An Analysis of Mechanical Constraints when Using Superconducting Gravimeters for Far-Field Pre-Seismic Anomaly Detection
}

\author{
Shyh-Chin Lan ${ }^{1}$, Teng-To $\mathrm{Yu}^{1,}{ }^{*}$, Cheinway Hwang ${ }^{2}$, and Ricky Kao ${ }^{2}$ \\ ${ }^{1}$ Department of Resources Engineering, National Cheng Kung University, Tainan, Taiwan \\ ${ }^{2}$ Department of Civil Engineering, National Chiao Tung University, Hsinchu, Taiwan
}

Received 13 May 2010, accepted 12 November 2010

\begin{abstract}
Pre-seismic gravity anomalies from records obtained at a $1 \mathrm{~Hz}$ sampling rate from superconducting gravimeters (SG) around East Asia are analyzed. A comparison of gravity anomalies to the source parameters of associated earthquakes shows that the detection of pre-seismic gravity anomalies is constrained by several mechanical conditions of the seismic fault plane. The constraints of the far-field pre-seismic gravity amplitude perturbation were examined and the critical spatial relationship between the SG station and the epicenter precursory signal for detection was determined. The results show that: (1) the preseismic amplitude perturbation of gravity is inversely proportional to distance; (2) the transfer path from the epicenter to the SG station that crosses a tectonic boundary has a relatively low pre-seismic gravity anomaly amplitude; (3) the pre-seismic gravity perturbation amplitude is also affected by the attitude between the location of an SG station and the strike of the ruptured fault plane. The removal of typhoon effects and the selection of SG stations within a certain intersection angle to the strike of the fault plane are essential for obtaining reliable pre-seismic gravity anomaly results.
\end{abstract}

Key words: Earthquake, Pre-seismic gravity anomaly, Superconducting gravimeter

Citation: Lan, S. C., T. T. Yu, C. Hwang, and R. Kao, 2011: An analysis of mechanical constraints when using superconducting gravimeters for far-field pre-seismic anomaly detection. Terr. Atmos. Ocean. Sci., 22, 271-282, doi: 10.3319/TAO.2010.11.12.01(T)

\section{INTRODUCTION}

A superconducting gravimeter ( $\mathrm{SG}$ ) is a spring-type gravimeter that is used for long-term gravity observation. The mechanical spring is replaced by a magnetically levitated superconducting sphere (Goodkind 1999). The voltage signals indicate the sphere's displacement from its null position, which is proportional to the gravity. Calibration is performed using parallel observations of an absolute gravimeter and the SG.

SGs are the most sensitive and stable instruments for gravity measurement (Iwano and Fukuda 2004). A 1 nanoGal sensitivity and a $1 \mathrm{~Hz}$ sampling rate make SGs very useful for detecting internal gravity waves inside the earth, and thus for determining the influence of environmental effects on gravity (Ikeda et al. 2005). A series of co-seismic gravity perturbations were detected and analyzed using SGs to demonstrate their sensitivity, with results compared with those obtained by seismometers (Imanishi et al. 2004; Hwang et

\footnotetext{
* Corresponding author

E-mail:yutt@mail.ncku.edu.tw
}

al. 2009; Kim et al. 2009; Nawa et al. 2009). The gravity signal of an SG is influenced by many natural events, including free oscillations of the Earth after a strong earthquake (Virtanen 1996; Park et al. 2005; Arora et al. 2008), seismic background noise (Virtanen 1998), the gravity effects of hydrological phenomena (Virtanen 2000, 2001), and variation in atmospheric mass (Virtanen and Mäkinen 2003; Virtanen 2004). SGs are suitable for long-term background gravity observation with fully automatic recording and data handling to reduce possible human error. For Global Positioning System (GPS) continuous tracking stations, long-time series of gravity readings are needed for outlier rejection to obtain more consistent analyses (Yang et al. 2007).

The search for earthquake precursors has been carried out for years. Studies have claimed that the ionosphere might be disturbed before strong earthquakes (Chuo et al. 2002; Liu et al. 2001, 2009; Zhao et al. 2009). Some studies suggested that pre-seismic surface vertical deformation detectable using InSAR may be linked to strong earthquakes (Shan et al. 2009). An amplitude increase and a phase-delay 
decrease below 6 millihertz were short-term slow precursors before the main shock as revealed by Ihmlé et al. (1993) in the slow-frequency spectra of the 1989 Macquarie Ridge earthquake (magnitude 8.2). The seismic moment released in such a slow precursor is equivalent to a regular seismic event of magnitude 7.6.

When tide and trend signals are removed from the SG long-term gravity records, tremors with gradually increasing and decreasing amplitudes are often found in the wave form. Some of the tremors are caused by typhoons, and the source of some tremors can be linked to earthquakes both temporally and spatially. Pre-seismic anomalies are correlated to the distance between the epicenter and a gravity station, and the source parameters of the earthquake, especially the relative position of the SG to the strike of the ruptured fault plane. Therefore, this study examines the constraints of detecting pre-seismic gravity amplitude perturbations and the spatial relationship of the SG to the epicenter. To study the spatial characteristics of pre-seismic gravity anomalies, data from four SG stations were analyzed.

\section{METHODS}

\subsection{SG Stations and Data}

The SG data used in this study were obtained from the ES, BA, MA, and HS stations. The station information is listed in Table 1 (retrieved 24 August 2010, from http:// www.eas.slu.edu/GGP/ggpstations.html). The ES, BA, and MA data were obtained from the National Astronomical Observatory of Japan (NAOJ) and the Ocean Hemisphere Project Data Management Center (OHP DMC). The HS SG data are supported by the Department of Land Administration, Ministry of the Interior, Taiwan. The time durations of SG data for each station are shown in Fig. 1. SG records obtained at a $1 \mathrm{~Hz}$ sampling rate were used in this study. The gravity residual values were obtained by removing the effects of body and ocean tides from the raw records, as suggested by Hwang et al. (2009). These effects were removed using Tsoft (Van Camp et al. 2005) and ETERNA (Wenzel 1996) software packages. Furthermore, frequencies below $0.005 \mathrm{~Hz}$ were filtered to ensure that the tide did not affect the value of gravity residuals.

\subsection{Identification of Pre-Seismic Gravity Anomalies and Comparison of Elastic Rebound Theory}

For a seismic precursor, an obvious gradually increasing and decreasing amplitude can be found before and after the main shock, respectively, as shown in Fig. 2a. From the time-frequency analysis, the spectrum of the high-resolution gravity data is concentrated within a certain range of frequencies prior to the rupture of the main shock at certain stations only, as shown in Fig. 2b.

The suggested theory for such earthquake-related phenomena is the elastic rebound. During the period of pre-seismic activity, strains build up on opposite sides of the fault; the fault is presumably locked at this period. When the accumulated strains exceed the frictional strength of the fault interface, an earthquake occurs, accompanied by a release of energy. After the main shock, the released stress gradually stabilizes as time goes by in the vicinity of the fault plane. Within the observed gravity anomaly, the increasing amplitude prior to the main shock suggests a stage of strain accumulation. The amplitude of a gravity perturbation decreases after the main shock, which can also be explained by the process of released stress gradually stabilizing.

Table 1. BA, ES, MA, and HS SG station information.

\begin{tabular}{lllll}
\hline Station ID & \multicolumn{1}{c}{ ES } & \multicolumn{1}{c}{ MA } & BA & GWR T048 \\
\hline Instrument & GWR T007 TT70 & GWR T011 TT70 & GWR T008 TT70 & Hsinchu, Taiwan \\
Location & Mt. Abara, Esashi, Japan & Matsushiro, Japan & Bandung, Indonesia & 24.792579 \\
Latitude (N) & 39.1511 & 36.5439 & -6.8964 & 120.985543 \\
Longitude (E) & 141.3318 & 138.2032 & 107.6317 & 87.601 \\
Height (m) & $433.76 \pm 0.2$ & $409.5 \pm 0.1$ & 713 & 2006.04 .16 \\
Start Ops & 1988.02 .02 & 1995.12 .07 & 1997.12 .16 & April 2006 \\
Start Record & 1997.10 .22 & 1995.12 .07 & 1997.12 .19 & - \\
End Record & - & - & April 2004 & 1 \\
Sampling (s) & 1 & 1 & 1 & 1 \\
Recording (s) & 1 & 1 & 0.001 & -52.23 \\
Precision (mV) & 0.01 & $-92.8790 \pm 0.0360$ & & -76.504 \\
Calibration (microgal/V) & $-56.082 \pm 0.029$ & & & 1 \\
\hline
\end{tabular}




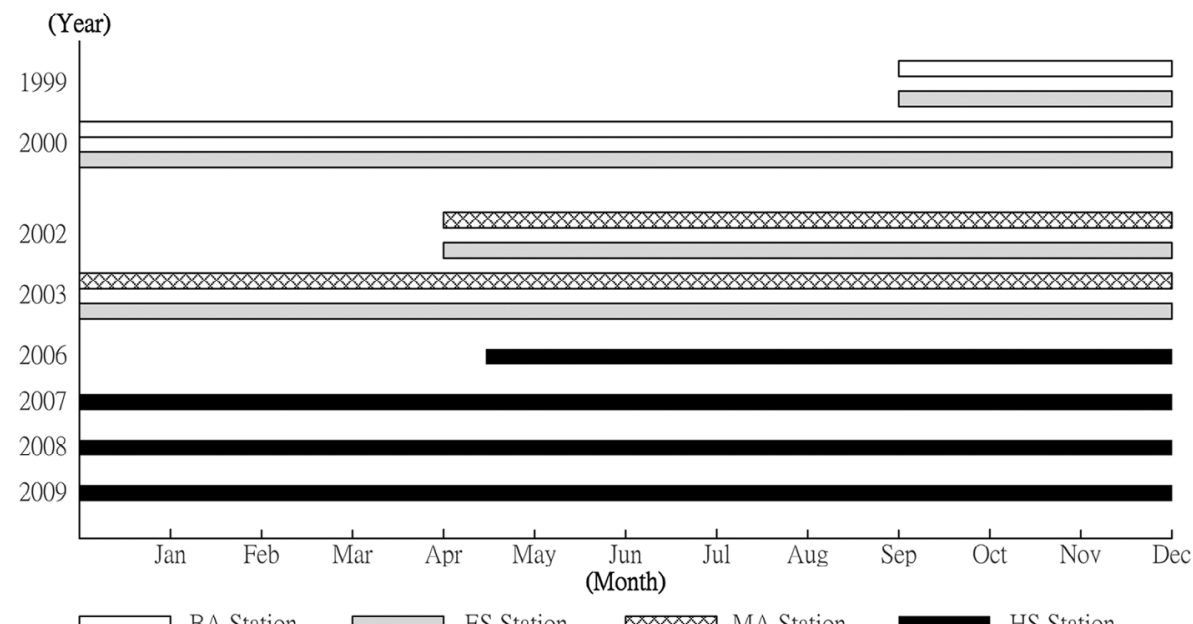

Fig. 1. Time durations of SG data used in this study.

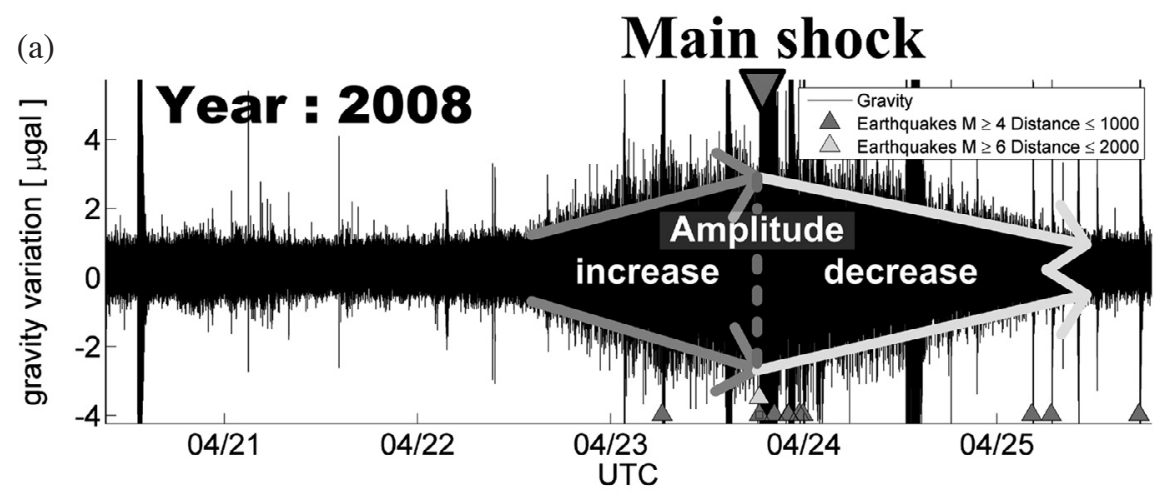

(b)

Main Shock
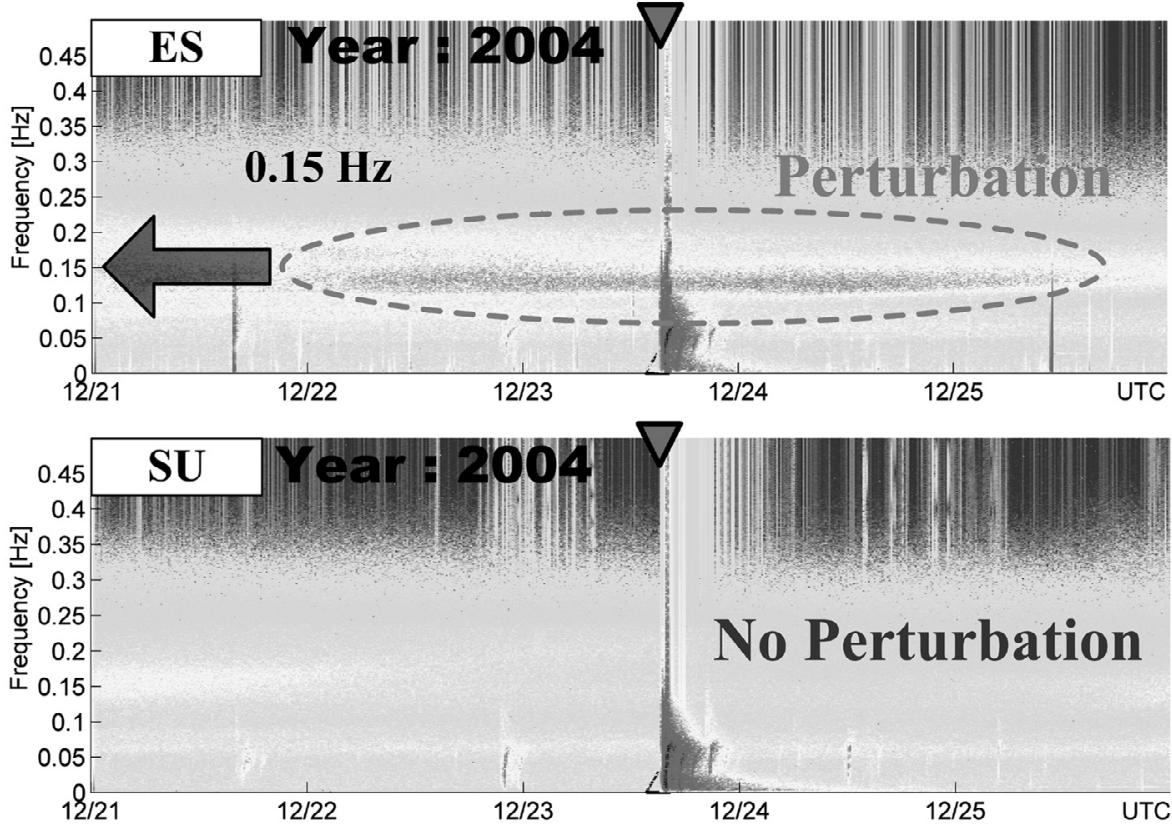

Fig. 2. (a) Example of successful gravity anomaly detection using SG records before and after the main shock of an earthquake. (b) Time-frequency analysis of data with pre-seismic anomaly events (ES station located at Esashi, Japan) and without perturbation events (SU station located at Sutherland, South Africa). 
According to Rundle (1978) and Walsh and Rice (1979), the gravity change caused by an earthquake decreases by the factor of inverse distance. Therefore, SG data from two stations at similar distances like ES and MA stations, are useful for identifying possible pre-seismic anomalies. Figure 3a shows the waveform of a pre-seismic gravity anomaly caused by an earthquake. The distances from the epicenter to each SG station are show in Fig. 3c. In Fig. 3b, the amplitude envelope of the ES station is converted using the ratio of inverse distance, making it very similar to data for the MA station. In general, to indentify a pre-seismic anomaly caused by a local earthquake, more data from a station adjacent to the epicenter is needed. However, the SG stations are scattered around the world. Pre-seismic gravity anomaly events must thus be analyzed using data from just a very few SG stations. Therefore, pre-seismic events should be strictly selected and verified. In addition, excluding the influence of typhoons, the magnitude of an earthquake should be taken into consideration. Normally, a pre-seismic gravity anomaly caused by a large earthquake is much more obvious than that caused by a small one. The events of a pre-seismic gravity anomaly are often found in the data for large magnitude earthquakes.

(a)
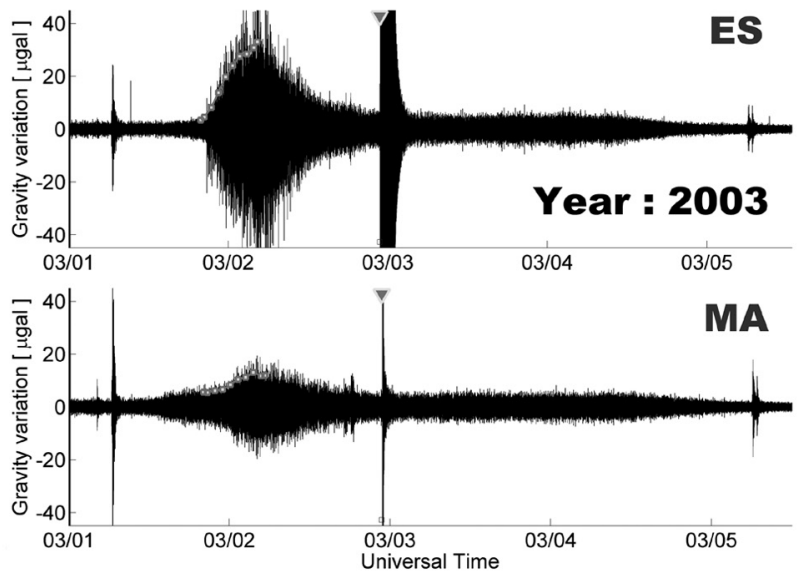

(b)

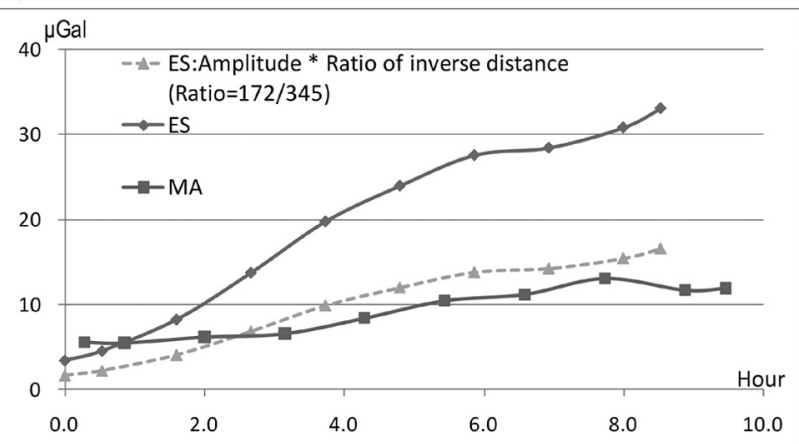

\subsection{Exclusion of Non-Seismic Tremors Caused by Typhoons}

Typhoons are powerful atmospheric perturbations. It has been suggested that typhoons may trigger slow earthquakes (Liu et al. 2009). Furthermore, in addition to the effects of low pressure and abundant precipitation, strong ocean waves caused by the strong wind of a typhoon can also disturb the gravity records of an SG. Figure 4 shows the gravity records of an SG during typhoons Gloria and Kirogi. Perturbations within the SG records gradually increased as the typhoons approached land. The typhoon tracks in Fig. 4 were downloaded from the Kitamoto Laboratory (Digital Typhoon 2009). This gravity anomaly is similar to the case of a pre-seismic perturbation. In a time-frequency analysis, obvious increases of data frequency were found at times A and B in direct association of a typhoon. In contrast, a seismic-related gravity anomaly is smoothly distributed within the frequency domain, as shown in Fig. 2b. When a typhoon made landfall on 3 July 2000 (refer to the typhoon report, http://www.data.jma.go.jp/obd/stats/data/bosai/report/ 2000/20000703/20000703.html), another perturbation with tight spikes was found in both the time and frequency domains, as shown by the dashed line in Fig. 4b for typhoon Kirogi.

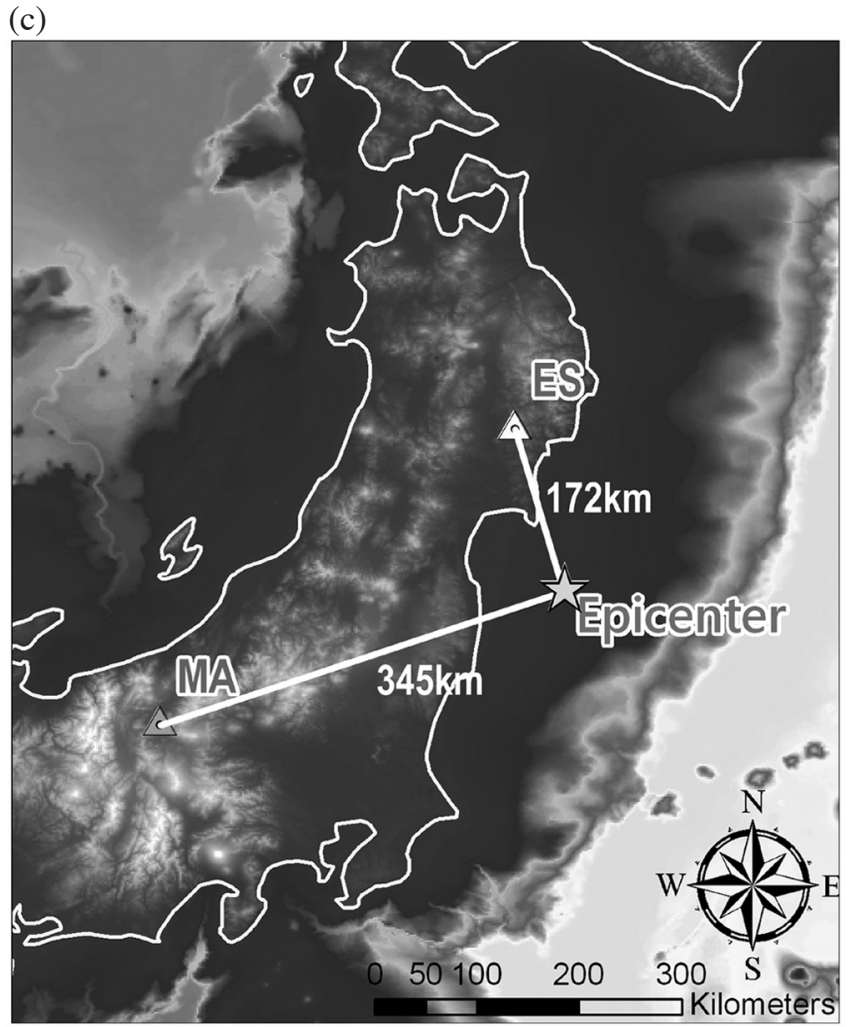

Fig. 3. (a) Pre-seismic anomaly waveforms of ES and MA SG stations. (b) After a conversion using the ratio of inverse distance, the amplitude envelope of the ES station is similar to that of the MA station. (c) The source of a pre-seismic grvity anomaly event located using the ratio of amplitude and the inverse distance from two SG stations to the epicenter of a possible earthquake. 


\subsection{Constraints of Pre-Seismic Anomalies}

To understand the spatial correlation between the rupture mechanics of the fault plane and the pre-seismic gravity anomaly, the relative positions of the strike and the magni- tude of the main shock are compared to the amplitude of the pre-seismic gravity anomaly. The relationship between the amplitude of a pre-seismic gravity anomaly and the distance from the epicenter to the SG station is also analyzed. (a)

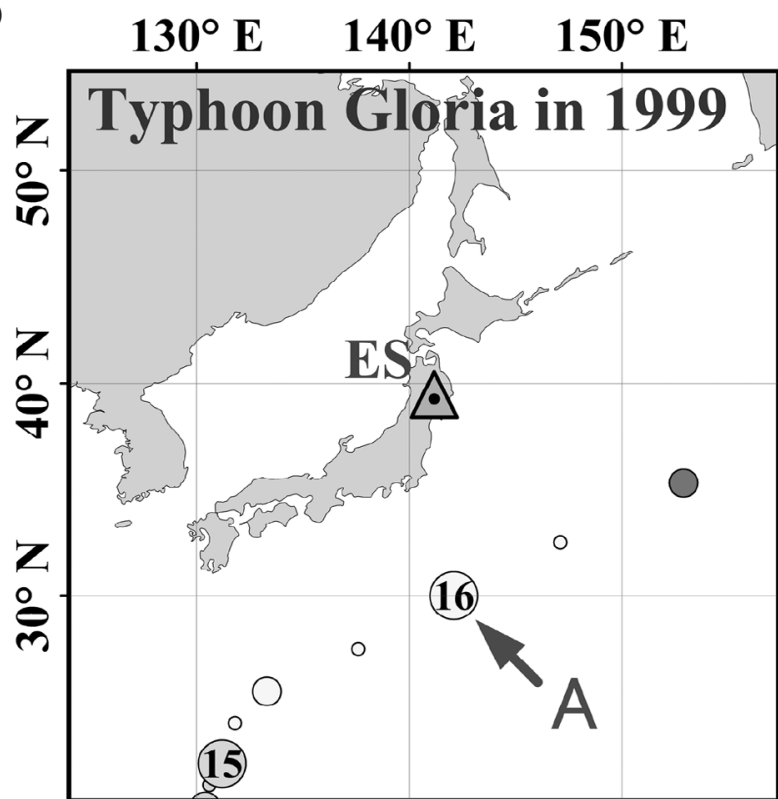

Typhoon Intensity o Severe Tropical Storm

- Tropical Depression • Typhoon

- Tropical Storm

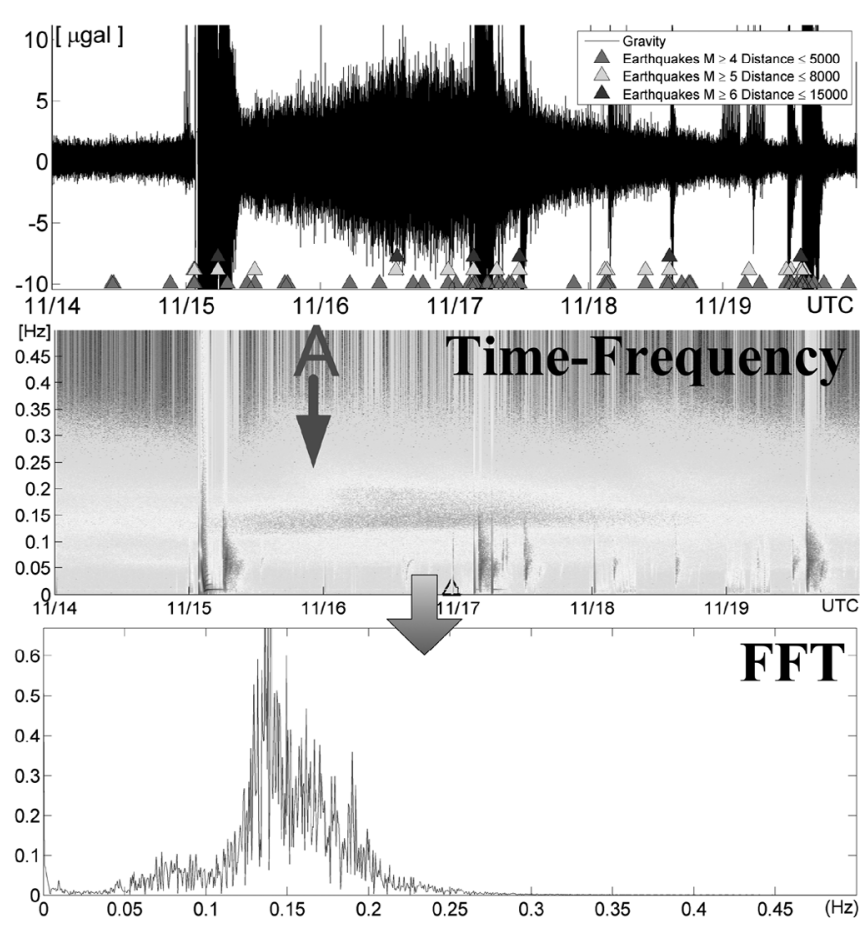

(b)
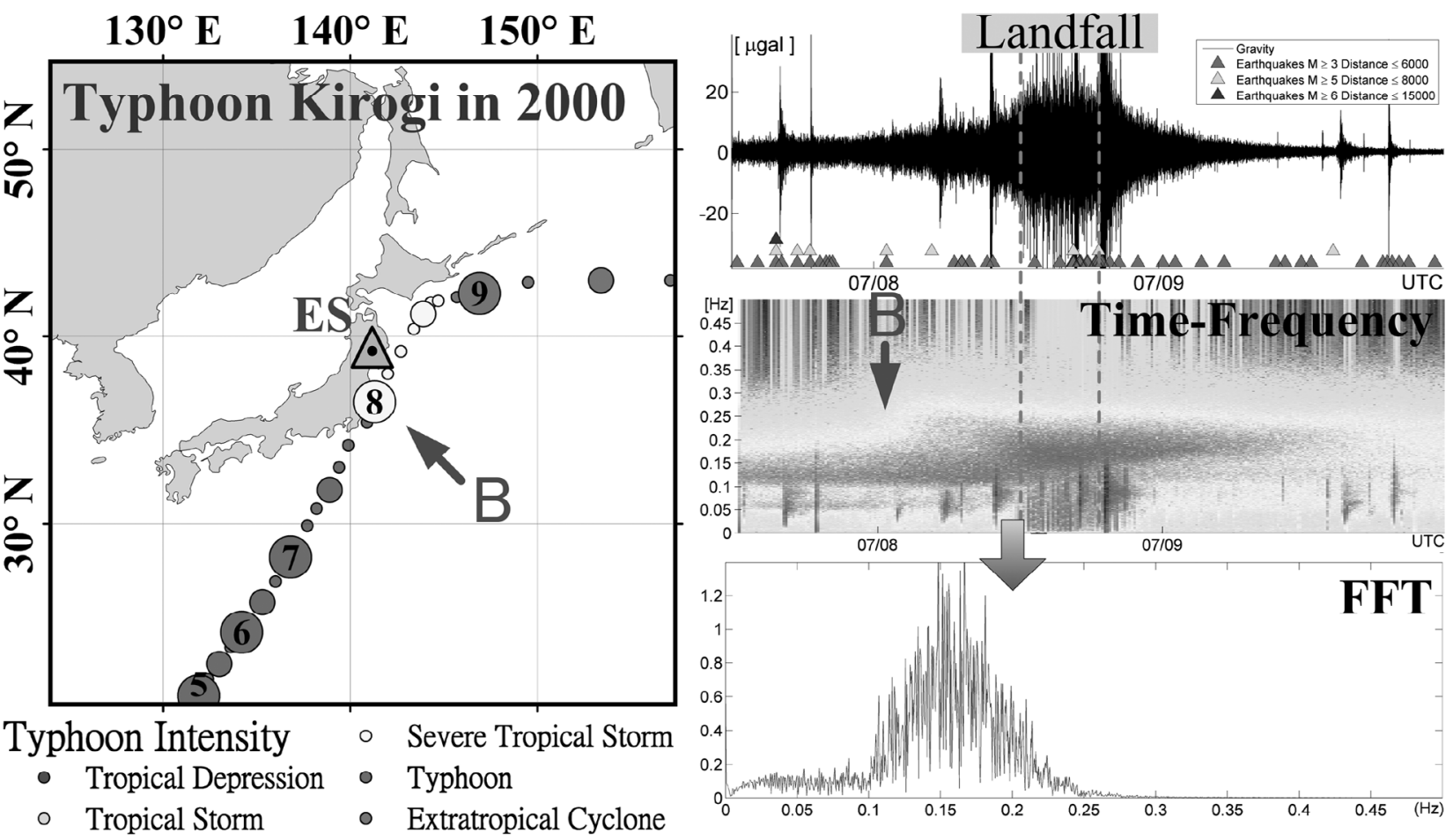

Fig. 4. Gravity perturbations caused by typhoons Gloria and Kirogi. (a) The track (left) and the gravity anomaly (right) of typhoon Gloria. (b) The track (left) and the gravity anomaly (right) of typhoon Kirogi. A and B indicate the typhoon tracks being close to land. 


\section{CONSTRAINT CONDITIONS AND OBSERVA-} TIONS

3.1 Linear Relationship Between the Pre-Seismic Gravity Anomaly Amplitude and the Inverse of Distance

Fourteen pre-seismic gravity anomalies for seven earthquakes were detected and identified by the ratio of am- plitude at ES and MA stations from May 2002 to March 2003; other events were detected by ES, BA, and HS stations. The data are listed in Table 2.

Figure 5 shows the distribution of the studied epicenters, the locations of the ES, MA, and HS stations, and the tectonic boundaries. An examination of the relationship of

Table 2. Detected pre-seismic anomaly events for BA, ES, MA, and HS SG stations.

\begin{tabular}{|c|c|c|c|c|c|c|c|c|c|}
\hline Event & Date & Time (UT) & Latitude & Longitude & $\mathbf{M}_{\mathrm{w}}$ & $\begin{array}{c}\text { Depth } \\
(\mathbf{k m})\end{array}$ & $\begin{array}{c}\text { SG } \\
\text { station }\end{array}$ & $\underset{(\mu \mathrm{Gal})}{\text { Amplitude }}$ & $\begin{array}{c}\text { Distance }^{*} \\
(\mathbf{k m})\end{array}$ \\
\hline \multirow{2}{*}{01} & \multirow{2}{*}{2002.05 .31} & \multirow{2}{*}{ 06:09:22 } & \multirow{2}{*}{52.76} & \multirow{2}{*}{171.81} & \multirow{2}{*}{5.5} & \multirow{2}{*}{30} & ES & 1.5 & 2745 \\
\hline & & & & & & & MA & 1.5 & 3133 \\
\hline \multirow{2}{*}{02} & \multirow{2}{*}{2002.11 .09} & \multirow{2}{*}{$19: 56: 53$} & \multirow{2}{*}{2.42} & \multirow{2}{*}{128.97} & \multirow{2}{*}{5.2} & \multirow{2}{*}{43} & ES & 4.3 & 4163 \\
\hline & & & & & & & MA & 4.8 & 3822 \\
\hline \multirow{2}{*}{03} & \multirow{2}{*}{2003.01 .28} & \multirow{2}{*}{ 06:09:00 } & \multirow{2}{*}{41.05} & \multirow{2}{*}{143.26} & \multirow{2}{*}{5.2} & \multirow{2}{*}{35} & ES & 12.6 & 269 \\
\hline & & & & & & & MA & 7.1 & 665 \\
\hline \multirow{2}{*}{04} & \multirow{2}{*}{2003.02 .11} & \multirow{2}{*}{ 06:01:00 } & \multirow{2}{*}{43.16} & \multirow{2}{*}{147.86} & 4 & 11 & $\mathrm{ES}$ & 8.8 & 705 \\
\hline & & & & & 4 & 11 & MA & 2.9 & 1102 \\
\hline 05 & & & & 13012 & 20 & 0 & ES & 26.5 & 257 \\
\hline 05 & 2003.02 .21 & 22:42:00 & 37.62 & 139.12 & 2.9 & 0 & MA & 24.6 & 146 \\
\hline 06 & 00030302 & $22 \cdot 17.00$ & 3760 & 14170 & 57 & 44 & ES & 33.1 & 172 \\
\hline 00 & 2003.05 .02 & 22.41 .00 & 31.09 & 141.19 & 5.1 & 44 & MA & 11.9 & 345 \\
\hline 07 & 00030328 & $17 \cdot 31.55$ & 15.15 & 173.34 & 60 & 40 & ES & 6.1 & 7157 \\
\hline 07 & 2003.03 .28 & 17:31:55 & -15.15 & $-1 / 3.34$ & 6.2 & 49 & MA & 5.7 & 7174 \\
\hline 08 & 2006.04 .15 & $22: 40: 54$ & 22.85 & 121.31 & 5.72 & 12 & HS & 3.7 & 218 \\
\hline 09 & 2007.02 .01 & $10: 43: 34$ & 1.30 & 126.34 & 5.4 & 40 & HS & 2.5 & 2635 \\
\hline 10 & 2007.02 .14 & 19:50:02 & 0.33 & 97.22 & 5.7 & 12 & HS & 3.6 & 3668 \\
\hline 11 & 2007.03.11 & 07:09:29 & 43.97 & 148.18 & 5.7 & 58 & HS & 3.5 & 3207 \\
\hline 12 & 2007.03.17 & $17: 42: 32$ & 1.30 & 126.37 & 6.3 & 41 & HS & 4.1 & 2635 \\
\hline 13 & 2007.04 .18 & 01:08:15 & -24.20 & -66.90 & 5.6 & 218 & HS & 3.0 & 12506 \\
\hline 14 & 2008.01 .13 & $12: 15: 39$ & 17.26 & 120.80 & 5.8 & 20 & HS & 6.2 & 833 \\
\hline 15 & 2008.04 .23 & $18: 28: 42$ & 22.89 & 121.66 & 5.57 & 10 & HS & 2.5 & 222 \\
\hline 16 & 2008.11 .30 & 00:38:59 & 18.12 & 147.21 & 5.6 & 17 & HS & 1.9 & 2785 \\
\hline 17 & 2008.12 .30 & $19: 49: 56$ & -4.63 & 100.89 & 6 & 23 & HS & 5.1 & 3846 \\
\hline 18 & 2009.01 .23 & $12: 38: 15$ & 21.10 & 121.23 & 5.4 & 12 & HS & 7.4 & 409 \\
\hline 19 & 2009.02 .17 & $00: 12: 59$ & 37.54 & 141.61 & 5 & 58 & HS & 5.2 & 2388 \\
\hline 20 & 2009.03 .06 & $10: 50: 32$ & 80.33 & -2.32 & 6.5 & 13 & HS & 4.4 & 7380 \\
\hline 21 & 2009.04 .01 & $14: 27: 49$ & -3.80 & 100.39 & 5.4 & 20 & HS & 4.2 & 3804 \\
\hline 22 & 2009.04 .26 & 00:06:58 & -30.19 & -178.24 & 6.1 & 152 & HS & 3.6 & 8087 \\
\hline 23 & 2009.11 .17 & 00:39:10 & 5.86 & 127.13 & 5.2 & 100 & HS & 7.6 & 2170 \\
\hline 24 & 2009.12 .14 & 03:05:26 & -9.99 & 123.80 & 5.5 & 35 & HS & 1.7 & 3790 \\
\hline 25 & 2009.12 .19 & $13: 02: 15$ & 23.78 & 121.75 & 6.26 & 46 & HS & 4.8 & 143 \\
\hline A-1 & 2000.03 .21 & 05:26:07 & 3.15 & 128.03 & 5.9 & 102 & BA & 6.1 & 2490 \\
\hline A-2 & 2000.03 .27 & 18:57:55 & 1.6 & 127.35 & 4.5 & 132 & BA & 3.9 & 2349 \\
\hline B-1 & 1999.10 .10 & 07:03:04 & -1.99 & 134.28 & 6 & 33 & $\mathrm{BA}$ & 4.8 & 2970 \\
\hline B-2 & 2000.08 .12 & $10: 26: 15$ & -3.07 & 136.11 & 6.1 & 33 & $\mathrm{BA}$ & 2.5 & 3144 \\
\hline
\end{tabular}


Table 2. (Continued)

\begin{tabular}{|c|c|c|c|c|c|c|c|c|c|}
\hline Event & Date & Time (UT) & Latitude & Longitude & $\mathbf{M}_{\mathrm{w}}$ & $\begin{array}{c}\text { Depth } \\
(\mathbf{k m})\end{array}$ & $\begin{array}{c}\text { SG } \\
\text { station }\end{array}$ & $\begin{array}{c}\text { Amplitude } \\
(\mu \mathrm{Gal})\end{array}$ & $\begin{array}{c}\text { Distance } \\
(\mathbf{k m})\end{array}$ \\
\hline $\mathrm{C}-1$ & 2000.10 .16 & 18:09:31 & -5.48 & 101.72 & 5.1 & 33 & BA & 2.7 & 672 \\
\hline $\mathrm{C}-2$ & 2000.06 .26 & $16: 55: 50$ & -5.48 & 102.54 & 4.5 & 33 & BA & 8.4 & 584 \\
\hline $\mathrm{C}-3$ & 2000.11 .10 & $10: 48: 11$ & -5.63 & 103.01 & 5.1 & 33 & BA & 5.1 & 530 \\
\hline D-1 & 2000.02 .12 & 03:11:02 & -8.7 & 112.44 & 5.3 & 107 & BA & 1.8 & 572 \\
\hline D-2 & 2000.09 .27 & $13: 58: 42$ & -9.07 & 113.16 & 4.8 & 33 & BA & 4.3 & 654 \\
\hline E & 2000.02 .03 & $09: 15: 22$ & 13.57 & 121.55 & 5.5 & 33 & BA & 2.8 & 2958 \\
\hline F & 1999.10.21 & $13: 42: 25$ & 13.73 & 125.2 & 5.5 & 42 & BA & 3.9 & 2708 \\
\hline G & 2000.03 .10 & $21: 32: 12$ & 4.74 & 96.01 & 5.6 & 33 & BA & 2.2 & 1812 \\
\hline $\mathrm{H}$ & 2000.06 .03 & 03:54:45 & 51.92 & 158.93 & 5.5 & 76 & ES & 1.2 & 1948 \\
\hline I & 1999.12.30 & $13: 21: 36$ & 47.58 & 154.51 & 5.6 & 33 & ES & 5.5 & 1411 \\
\hline $\mathrm{J}$ & 1999.11.01 & $13: 25: 16$ & 39.9 & 113.98 & 5.3 & 10 & ES & 7.7 & 2329 \\
\hline K-1 & 1999.10.21 & $09: 15: 22$ & 13.73 & 125.2 & 5.6 & 42 & ES & 8.7 & 3187 \\
\hline $\mathrm{K}-2$ & 2000.01 .21 & $03: 12: 00$ & 13.15 & 125.2 & 5.7 & 33 & ES & 6.7 & 3220 \\
\hline
\end{tabular}

* Straight line distance.

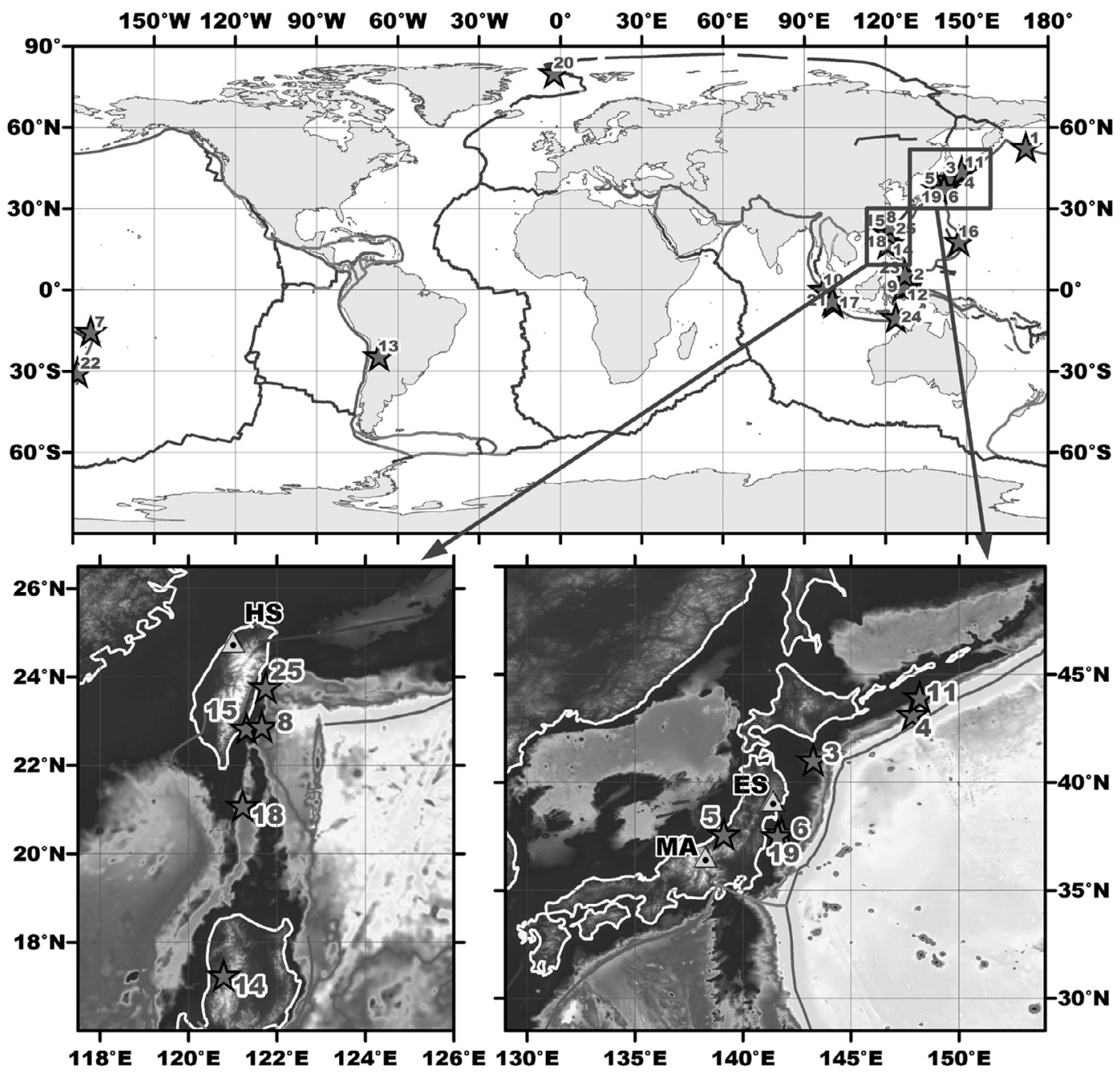

Fig. 5. Locations of the epicenters (stars) and SG stations (triangles) of earthquake events 01 to 18 in Table 1. 
the pre-seismic gravity anomaly amplitude and the parameters of the earthquake reveals a simple linear relationship between the pre-seismic anomaly amplitude and the inversion of distance, as shown in Fig. 6.

Some of the pre-seismic anomalies detected within $1000 \mathrm{~km}$ of the epicenter do not follow a linear relationship. The paths between epicenters and SG stations of the detected events pass through tectonic boundaries. The detected amplitudes of these events are much lower than those of events within the same tectonic plate. However, this effect did not appear for events with a longer epicenter to SG station distances implying that decay in the amplitude is not solely controlled by the increase of distance only. The concentration of strain at one side of a fault plane induces gravity traction in the direction to the station; when a tectonic boundary is crossed, this mechanism might generate a couple of forces with reverse directions at the opposite side of the boundary. This force might affect the gravity station, thus reducing the recorded amplitude of the gravity perturbation. However, this effect, which is much smaller than the directional effect associated with the fault plane, decays very quickly. Thus, this phenomenon is only found for seismic events very close to SG stations. In addition, the amplitude of pre-seismic anomalies does not seem to be directly associated with the seismic moment.

\subsection{Pre-Seismic Gravity Anomaly Amplitude Relation- ship to the Position of SG Sstations and the Strike of the Fault Plane}

For most earthquakes, the maximum observed gravitational change is in the direction perpendicular to the strike. This also affects the amplitude of a pre-seismic anomaly.
To examine this tendency, pre-seismic gravity anomalies with seismic moments of $5.5-5.6$ that were detected by BA and ES stations are shown in Fig. 7. The blue, green, and brown lines in Fig. 7 denote the tectonic boundaries (modified from Coffin et al. 1998).

For a comparison of the pre-seismic anomaly amplitude with relative positions of SG stations to the strike of the fault plane, six events (E - J) are list in Table 3. The distances from the epicenters to the SG stations are similar, but the amplitudes of the pre-seismic anomaly events located at the relative position of an SG parallel to the strike of the fault plane, such as events G, H, and I, are smaller than other events that are perpendicular. This suggests that the recorded amplitude of the pre-seismic gravity anomalies is also affected by the intersection angle between the strike of the fault plane and the bearing of the line connecting the epicenter to the gravity station. This might be due to the greatest underground mass difference being in the direction perpendicular to the strike of the fault plane.

\subsection{Correlation Between the Pre-Seismic Gravity Anomaly Amplitude and the Moment Magnitude of the Earthquake}

Eleven pre-seismic gravity anomalies are indicated by green stars in Fig. 7 and listed in Table 4. The anomalies are divided into 5 subgroups, shown as gray circles. In case A, the maximum gravity perturbation amplitudes increased with the moment magnitude of the earthquake. However, in the other cases, the recorded amplitudes of anomalies are not correlated with the seismic moments of the earthquakes. For cases $\mathrm{B}$ and $\mathrm{K}$, the moment magnitudes of the earthquakes and the distances to the epicenters are similar, respectively,

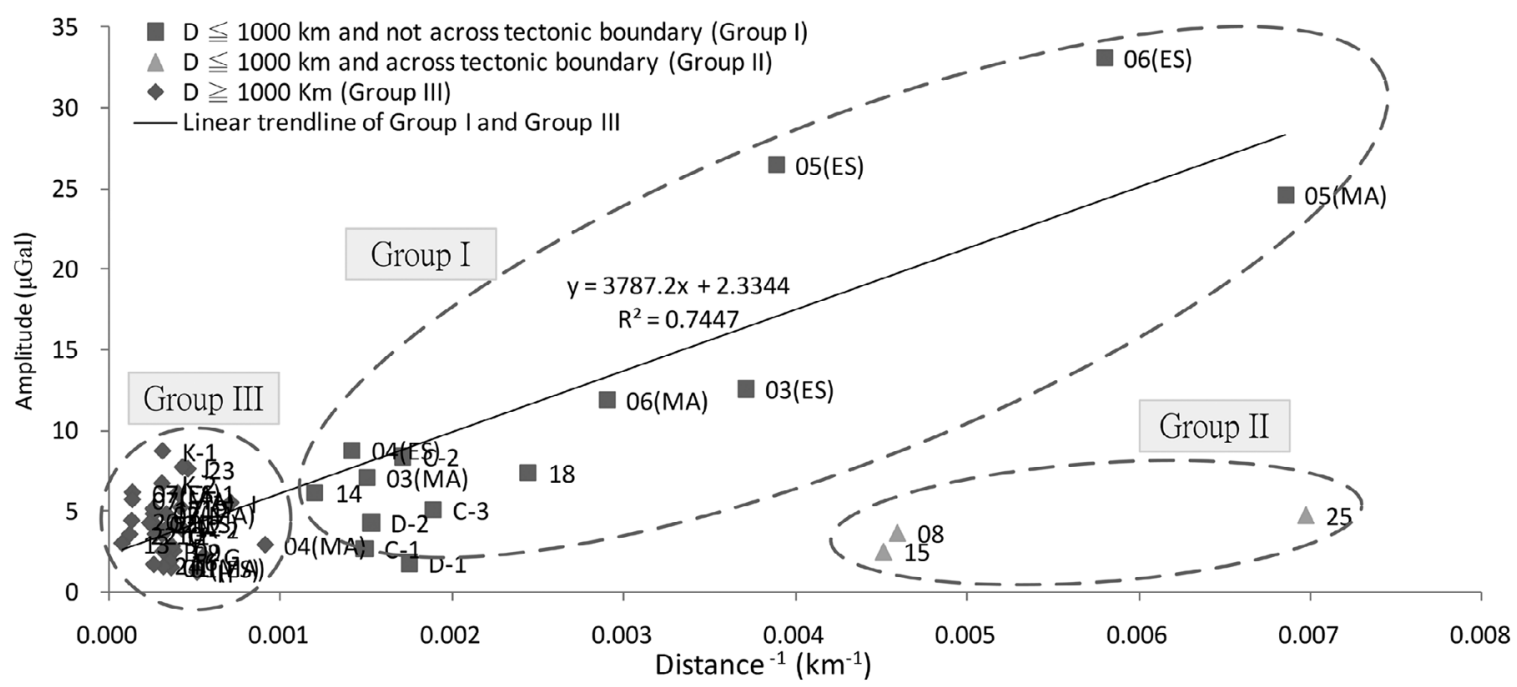

Fig. 6. Linear relationship between the pre-seismic gravity anomaly amplitude and the inverse of distance. The distance (D) of the epicenter to the stations in Group I and Group II are $\leq 1000 \mathrm{~km}$. The paths between the epicenters and stations of Group II pass through a tectonic boundary. Group III contains events with distance $\geq 1000 \mathrm{~km}$. 


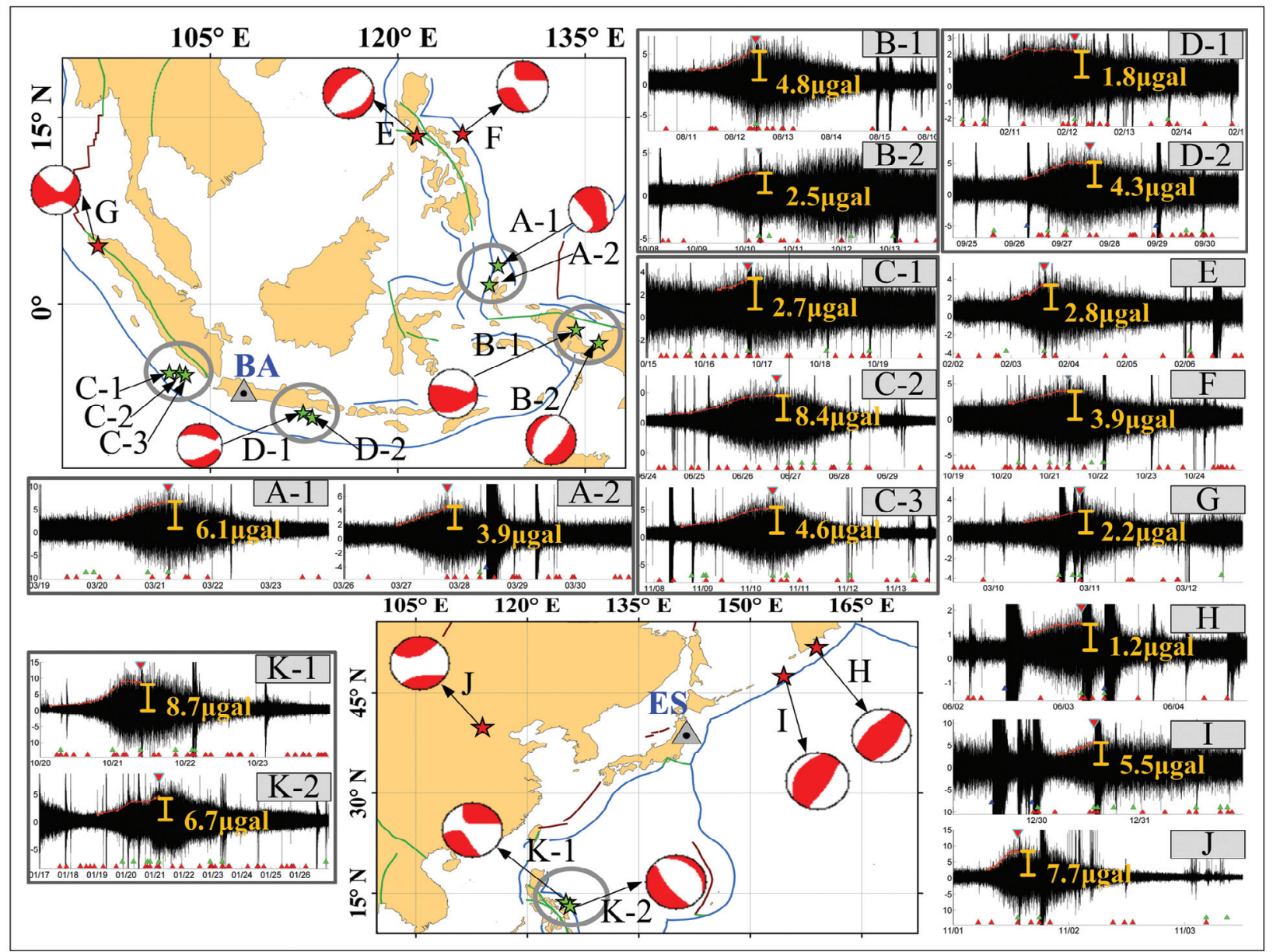

Fig. 7. Records and the distributions of pre-seismic gravity anomaly events. The red stars are the seismic events used to analyze the pre-seismic gravity anomaly amplitude relationship to the positions of SG stations and the strike of the fault plane. The green stars within the gray circles are the events used for comparison of the pre-seismic gravity anomaly amplitude relative to the seismic moment. The blue, green, and brown lines denote the trench, transform, and ridge boundaries, respectively.

Table 3. Comparison of pre-seismic anomaly amplitudes and relative positions of SGs.

\begin{tabular}{|c|c|c|c|c|c|c|}
\hline \multirow{2}{*}{ Event } & \multicolumn{3}{|c|}{ Comparison 1} & \multicolumn{3}{|c|}{ Comparison 2} \\
\hline & $\mathbf{E}$ & $\mathbf{F}$ & G & $\mathbf{H}$ & $\mathbf{I}$ & $\mathbf{J}$ \\
\hline $\mathrm{M}_{\mathrm{w}}$ & 5.5 & 5.5 & 5.6 & 5.5 & 5.6 & 5.3 \\
\hline $\mathrm{A}_{\mathrm{m}}(\mu \mathrm{Gal})^{*}$ & 2.8 & 3.9 & 2.2 & 1.2 & 5.5 & 7.7 \\
\hline Distance $(\mathrm{km})$ & 2958 & 2708 & 1812 & 1948 & 1411 & 2329 \\
\hline Relative position** & Perp. & Perp. & Para. & Para. & Para. & Perp. \\
\hline
\end{tabular}

* Pre-seismic anomaly amplitude.

** Perpendicular (Prep.), Parallel (Para.).

Table 4. Comparison of pre-seismic anomaly amplitudes and the moment magnitude of an earthquake.

\begin{tabular}{|c|c|c|c|c|c|c|c|c|c|c|c|}
\hline \multirow[b]{2}{*}{ Event } & \multicolumn{2}{|c|}{ Case A } & \multicolumn{2}{|c|}{ Case B } & \multicolumn{3}{|c|}{ Case $\mathrm{C}$} & \multicolumn{2}{|c|}{ Case D } & \multicolumn{2}{|c|}{ Case K } \\
\hline & A-1 & A-2 & B-1 & B-2 & C-1 & $\mathrm{C}-2$ & $\mathrm{C}-3$ & D-1 & D-2 & K-1 & K-2 \\
\hline $\mathrm{M}_{\mathrm{w}}$ & 5.9 & 4.5 & 6.0 & 6.1 & 5.1 & 4.5 & 5.1 & 5.3 & 4.8 & 5.6 & 5.7 \\
\hline $\mathrm{A}_{\mathrm{m}}(\mu \mathrm{Gal})^{*}$ & 6.1 & 3.9 & 4.8 & 2.5 & 2.7 & 8.4 & 5.1 & 1.8 & 4.3 & 8.7 & 6.7 \\
\hline Distance $(\mathrm{km})$ & 2490 & 2349 & 2970 & 3144 & 672 & 584 & 530 & 572 & 654 & 3187 & 3220 \\
\hline
\end{tabular}

* Pre-seismic anomaly amplitude. 
but there is a difference of over $30 \%$ for the amplitudes of pre-seismic gravity perturbation. Therefore, the correlation of the amplitude of pre-seismic gravity anomalies to the moment magnitude of an earthquake is not straightforward. To verify this, the amplitude of pre-seismic gravity anomaly events was multiplied by the distance to exclude the influence of distance, as shown in the scatter diagram of Fig. 8. The low R-square of the trend line indicates no significant correlation.

\subsection{Correlation of Intersection Angle Between the Azimuth from the Epicenter to an SG Station and Strike of the Fault Plane}

As mentioned in section 3.2, the amplitude of pre-seismic anomalies detected in the direction perpendicular to the strike of the fault plane is larger than that for events detected in the parallel direction to the same plane. To examine the correlation of the intersection angles and the pre-seismic gravity anomaly, a rose diagram of the intersection angles of 15 pre-seismic gravity anomaly events within a distance of $4000 \mathrm{~km}$ to the HS station is shown in Fig. 9. The angle of each bin is $20^{\circ}$. The maximum number of events occurs at an angle near $90^{\circ}$. Most of the events ( 10 out of the 15 total events) appear within angles of $90^{\circ} \pm 50^{\circ}$.

\section{DISCUSSION}

In the correlation of the angle between the direction from an epicenter to an SG station and the strike of the fault plane, the amplitude of the pre-seismic gravity anomaly with a parallel bearing is smaller than that for perpendicular events. This is most likely due to the largest difference of underground mass being in the direction perpendicular to the strike. A total of $135 \mathrm{M}_{\mathrm{w}} \geq 5.0$ earthquakes within a distance of $1000 \mathrm{~km}$ to the HS station during April 2006 to December 2009, was used to examine the influence of excluding typhoons and intersection angle constraints. The results are listed in Table 5. After excluding non-seismic tremor events and selecting earthquakes with intersection angles of $90^{\circ} \pm 50^{\circ}$, the number of detection events significantly increased (4-fold).

Although the pre-seismic gravity anomaly amplitude is not obviously associated with the moment magnitude of the earthquake, the pre-seismic gravity anomaly amplitude is inversely proportional to the straight line distance between the epicenter and an SG station. An obvious decay of the pre-seismic gravity anomaly amplitude was found in events located in the vicinity of a station that cross a tectonic boundary. In addition, the moment magnitudes of the earthquakes used in this study were above $\mathrm{M}_{\mathrm{w}}$ 5.0. This result indicates that the opportunity to observe a pre-seismic gravity anomaly increases with the magnitude of an earthquake. Most of the pre-seismic gravity anomalies in this study are located in the subduction zone due to the dip-slip fault creating most of the vertical underground mass imbalance, with induces gravity perturbations. Pre-seismic gravity perturbations are due to changes in crustal density caused by the deformation near the epicenter. A gravity anomaly change that results from the deformation caused by an earthquake has been calculated numerically using an elastic half-spaced model (Rundle 1978; Walsh and Rice 1979). The results show that the gravity is proportional to the local uplift and that it decreases by a factor of $1 /$ distance faster than a simple line mass. In the events of group I (see Fig. 6), the linear relationship between the pre-seismic gravity anomaly amplitude and the inverse of distance can be well explained by this result. With increasing distance, the amplitude decreases to a small value of about $5 \mu \mathrm{Gal}$.

Recently, various types of low-frequency tremor from the broadband seismic network data have been discovered in various regions of subduction zones since 2002 (e.g., Obara 2002; Ide et al. 2007; Wech and Creager 2007; Shelly et al. 2009). Many characteristics of those tremors are similar to

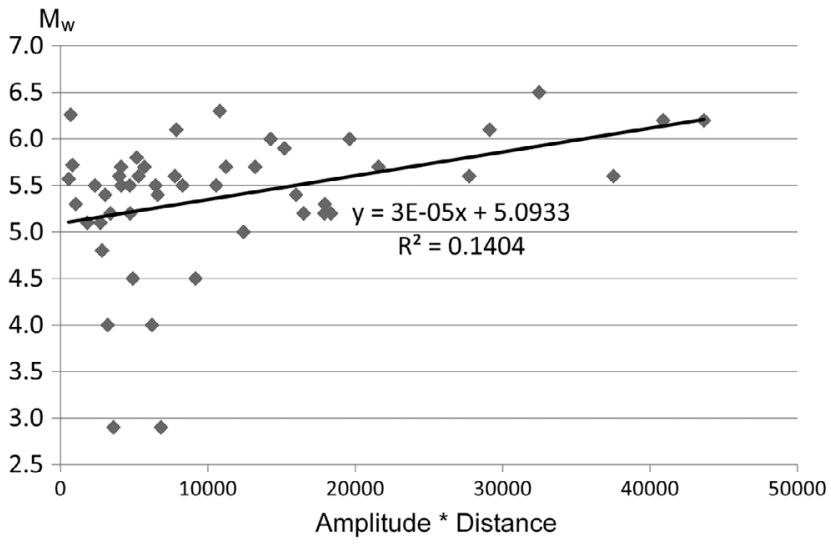

Fig. 8. Scatter diagram of the moment magnitude and the amplitude (in $\mu \mathrm{Gal}$ ) times distance (in kilometers). There is no straightforward correlation between the amplitude and the moment magnitude.

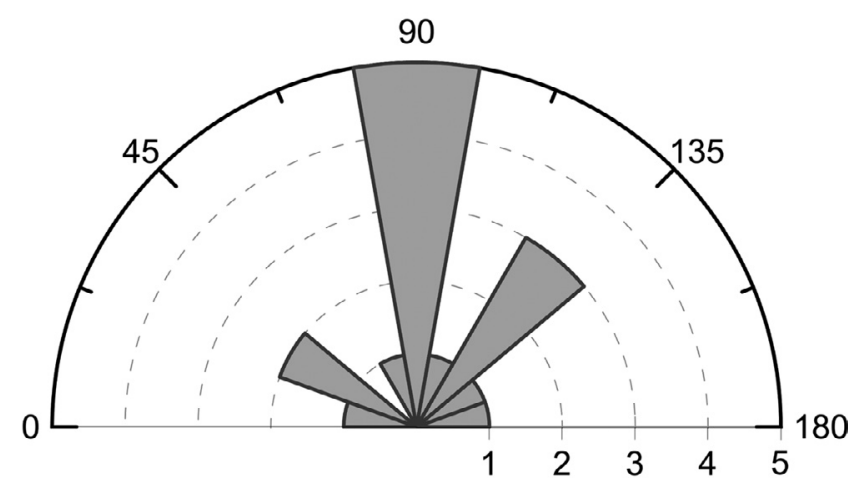

Fig. 9. Rose diagram of the intersection angles between the azimuths (from epicenters to the HS SG station) and the strike of the fault plane. 
Table 5. Comparison of the detection of pre-seismic gravity anomaly events under the constraints of intersection angles and excluding typhoon events.

\begin{tabular}{ccccc}
\hline \multicolumn{2}{c}{ Constraints } & $\begin{array}{c}\text { Number of pre-seismic } \\
\text { anomaly events (A) }\end{array}$ & $\begin{array}{c}\text { Total number of } \\
\text { earthquakes (E) }\end{array}$ & $\begin{array}{c}\text { Ratio } \\
\text { (A/E) }\end{array}$ \\
\hline Typhoons & Intersection angle & 5 & 135 & $3.7 \%$ \\
Included & $90^{\circ} \pm 90^{\circ}$ & 5 & 83 & $6.0 \%$ \\
Excluded & $90^{\circ} \pm 90^{\circ}$ & 49 & $6.4 \%$ \\
Excluded & $90^{\circ} \pm 70^{\circ}$ & 3 & 19 & $15.8 \%$ \\
Excluded & $90^{\circ} \pm 50^{\circ}$ & 3 & 4009.
\end{tabular}

the gravity anomalies in this study. However, the performance characteristics between the broadband seismometer and the SG are different. The high sensitive ability of SG can detect much tinier vibrations such as the gravity change caused by slow rate crustal deformation which is not detectable by a broadband seismometer. Although the chosen filter is $0.005 \mathrm{~Hz}$ for this study, the filter will obscure some but not all of signals. The spectrum analysis of most events shows that the frequency of significant perturbations is much higher than $0.005 \mathrm{~Hz}$.

\section{CONCLUSION}

SGs with a high sampling rate can be used to detect earthquake precursors if all the necessary constraints are removed. Global SG stations are useful for analyzing the spatial correlation of pre-seismic gravity anomaly events. Due to the condition variety of each event makes it difficult to find out all the constraints in this study. But the constraints carried out in this study can be a reasonable start to define the characters about pre-seismic gravity anomaly. The initial results suggest that: (1) the relationship between the amplitude and distance of a pre-seismic gravity anomaly is basically linear; (2) the amplitude may decay for pre-seismic gravity anomaly events close to the SG station that cross a tectonic boundary; (3) the pre-seismic gravity anomaly amplitude detected by an SG may be related to the intersection angle between the direction of waveform propagation to the strike of the fault plane.

Acknowledgements This work was supported in part by the National Science Council of Taiwan under grants NSC 93-2119-M-006-006, NSC 94-2116-M-006-016, NSC 952116-M-006-004, and NSC 97-2116-M-006-013. The superconducting gravity meter records used in this study are available from the National Astronomical Observatory of Japan (NAOJ), the Ocean Hemisphere Project Data Management Center (OHP DMC), and the Global Geodynamic Project Information System and Data Center (GGP-ISDC). We are very grateful to these centers for their data support and for answering technical questions during the preparation of this work. We would also like to thank Dr. Chi-Ching
Liu and another anonymous reviewer for their comments and suggestions, which significantly improved the quality of this manuscript.

\section{REFERENCES}

Arora, B. R., Kamal, A. Kumar, G. Rawat, N. Kumar, and V. M. Choubey, 2008: First observations of free oscillations of the earth from Indian superconducting gravimeter in Himalaya. Curr. Sci., 95, 1611-1617.

Chuo, Y. J., J. Y. Liu, S. A. Pulinets, and Y. I. Chen, 2002: The ionospheric perturbations prior to the Chi-Chi and Chia-Yi earthquakes. J. Geodyn., 33, 509-517, doi: 10. 1016/S0264-3707(02)00011-X. [Link]

Coffin, M. F., L. M. Gahagan, and L. A. Lawver, 1998: Present-day Plate Boundary Digital Data Compilation, UTIG Technical Report No. 174, University of Texas, Institute for Geophysics, Austin, Texas.

Digital Typhoon, 2009: Typhoon Images and Information, available at http://agora.ex.nii.ac.jp/digital-typhoon/.

Goodkind, J. M., 1999: The superconducting gravimeter. Rev. Sci. Instrum., 70, 4131-4152, doi: 10.1063/1.1150 092. [Link]

Hwang, C., R. Kao, C. C. Cheng, J. F. Huang, C. W. Lee, and T. Sato, 2009: Results from parallel observations of superconducting and absolute gravimeters and GPS at the Hsinchu station of Global Geodynamics Project, Taiwan. J. Geophys. Res., 114, B07406, doi: 10.1029/2008JB006195. [Link]

Ide, S., D. R. Shelly, and G. C. Beroza, 2007: Mechanism of deep low frequency earthquakes: Further evidence that deep non-volcanic tremor is generated by shear slip on the plate interface. Geophys. Res. Lett., 34, L03308, doi: 10.1029/2006GL028890. [Link]

Ihmlé, P. F., P. Harabaglia, and T. H. Jordan, 1993: Teleseismic detection of a slow precursor to the Great 1989 Macquarie Ridge Earthquake. Science, 261, 177-183, doi: 10.1126/science.261.5118.177. [Link]

Ikeda, H., K. Doi, Y. Fukuda, K. Shibuya, and R. Yoshizaki, 2005: Installation of superconducting gravimeter in the Antarctica. Physica C: Superconductivity, 426-431, 
759-763, doi: 10.1016/j.physc.2005.02.078. [Link] Imanishi, Y., T. Sato, T. Higashi, W. Sun, and S. Okubo, 2004: A network of superconducting gravimeters detects submicrogal coseismic gravity changes. Science, 306, 476-478, doi: 10.1126/science.1101875. [Link]

Iwano, S. and Y. Fukuda, 2004: Superconducting gravimeter observations without a tilt compensation system. Phys. Earth Planet. Inter., 147, 343-351, doi: 10.1016/j.pepi. 2004.08.001. [Link]

Kim, J. W., J. Neumeyer, T. H. Kim, I. Woo, H. J. Park, J. S. Jeon, and K. D. Kim, 2009: Analysis of superconducting gravimeter measurements at MunGyung station, Korea. J. Geodyn., 47, 180-190, doi: 10.1016/j. jog.2008.07.008. [Link]

Liu, C. C., A. T. Linde, and I. S. Sacks, 2009: Slow earthquakes triggered by typhoons. Nature, 459, 833-836, doi: 10.1038/nature08042. [Link]

Liu, J. Y., Y. I. Chen, Y. J. Chuo, and H. F. Tsai, 2001: Variations of ionospheric total electron content during the Chi-Chi earthquake. Geophys. Res. Lett., 28, 13811386, doi: 10.1029/2000GL012511. [Link]

Liu, J. Y., Y. I. Chen, C. H. Chen, C. Y. Liu, C. Y. Chen, M. Nishihashi, J. Z. Li, Y. Q. Xia, K. I. Oyama, K. Hattori, and C. H. Lin, 2009: Seismoionospheric GPS total electron content anomalies observed before the 12 May $2008 M_{w}$ 7.9 Wenchuan earthquake. J. Geophys. Res., 114, A04320, doi: 10.1029/2008ja013698. [Link]

Nawa, K., N. Suda, I. Yamada, R. Miyajima, and S. Okubo, 2009: Coseismic change and precipitation effect in temporal gravity variation at Inuyama, Japan: A case of the 2004 off the Kii peninsula earthquakes observed with a superconducting gravimeter. J. Geodyn., 48, 1-5, doi: 10.1016/j.jog.2009.01.006. [Link]

Obara, K., 2002: Nonvolcanic deep tremor associated with subduction in southwest Japan. Science, 296, 16791681, doi: 10.1126/science.1070378. [Link]

Park, J., T. R. A. Song, J. Tromp, E. Okal, S. Stein, G. Roult, E. Clevede, G. Laske, H. Kanamori, P. Davis, J. Berger, C. Braitenberg, M. V. Camp, X. Lei, H. Sun, H. Xu, and S. Rosat, 2005: Earth's free oscillations excited by the 26 December 2004 Sumatra-Andaman earthquake. Science, 308, 1139-1144, doi: 10.1126/science.1112305. [Link]

Rundle, J. B., 1978: Gravity changes and the Palmdale Uplift. Geophys. Res. Lett., 5, 41-44, doi: 10.1029/GL005i 001p00041. [Link]

Shan, X. J., X. G. Song, Y. F. Han, C. Y. Qu, G. F. Zhang, and G. H. Zhang, 2009: The characteristics of surface vertical deformation before the Wenchuan $M_{s} 8.0$ earthquake from InSAR. Chin. J. Geophys., 52, 27392745. (in Chinese)

Shelly, D. R., W. L. Ellsworth, T. Ryberg, C. Haberland, G. S. Fuis, J. Murphy, R. M. Nadeau, and R. Bürgmann, 2009: Precise location of San Andreas fault tremors near Cholame, California using seismometer clusters: Slip on the deep extension of the fault? Geophys. Res. Lett., 36, L01303, doi: 10.1029/2008GL036367. [Link]

Van Camp, M. and P. Vauterin, 2005: Tsoft: Graphical and interactive software for the analysis of time series and Earth tides. Comput. Geosci., 31, 631-640, doi: 10.1016/ j.cageo.2004.11.015. [Link]

Virtanen, H., 1996: Observations of free oscillations of the Earth by superconducting gravimeter GWR T020. Acta Geod. Geoph. Mont. Hung., 31, 423-431.

Virtanen, H., 1998: On superconducting gravimeter observations above $8 \mathrm{mHz}$ at the Metsähovi station, Finland. Reports of the Finnish Geodetic Institute 98:5.

Virtanen H., 2000: On the observed hydrological environmental effects on gravity at the Metsähovi station, Finland. In: Ducarme, B. and J. Barthelemy (Eds.), Proceedings of the Workshop: High Precision Gravity Measurements with Application to Geodynamics, and Second GGP Workshop, Munsbach Castle (Grand Duchy of Luxembourg), March $24^{\text {th }}$ to $26^{\text {th }}$, Cahiers du Centre Européen de Géodynamique et de Séismologie 17, 169-175.

Virtanen H., 2001: Hydrological studies at the gravity Station Metsähovi in Finland. J. Geod. Soc. Jpn., 47, 328333.

Virtanen, H., 2004: Loading effects in Metsähovi from the atmosphere and the Baltic Sea. J. Geodyn., 38, 407422, doi: 10.1016/j.jog.2004.07.018. [Link]

Virtanen, H. and J. Mäkinen, 2003: The effect of the Baltic Sea level on gravity at the Metsähovi station. $J$. Geodyn., 35, 553-565, doi: 10.1016/S0264-3707(03) 00014-0. [Link]

Walsh, J. B. and J. R. Rice, 1979: Local changes in gravity resulting from deformation. J. Geophys. Res., 84, 165170, doi: 10.1029/JB084iB01p00165. [Link]

Wech, A. G. and K. C. Creager, 2007: Cascadia tremor polarization evidence for plate interface slip. Geophys. Res. Lett., 34, L22306, doi: 10.1029/2007GL031167. [Link]

Wenzel, H. G., 1996, The nanoGal software: Earth tide processing package ETERNA 3.30. Bulletin d'Informations Marées Terrestres, 124, 9425-9439.

Yang, M., Y. F. Chen, F. Y. Chu, C. Hwang, and T. C. Cheng, 2007: Comparisons of geocentric height changes derived from absolute gravimetry and GPS at continuous tracking stations in Taiwan. First Asia Workshop on Superconducting Gravimetry Abstracts, March 12-15, Hsinchu, Taiwan, 30.

Zhao, B., M. Wang, T. Yu, W. Wan, J. Lei, L. Liu, and B. Ning, 2008: Is an unusual large enhancement of ionospheric electron density linked with the 2008 great Wenchuan earthquake? J. Geophys. Res., 113, A11304, doi: 10.1029/2008JA013613. [Link] 